\title{
Various Use of Cloud Computing with the Help of IP Camera based on Line
}

\author{
Vasudha Roy \\ Asst. Professor \\ Millia Institute of Technology \\ Purnea, Bihar
}

\author{
Md. Imran Alam \\ Asst. Professor \\ Millia Institute of Technology \\ Purnea, Bihar
}

\author{
Md. Shamsher Alam \\ H.O.D \\ Millia Institute of Technology \\ Purnea, Bihar
}

\begin{abstract}
In the global market competition the advancement in information and communication systems has become the challenging as well as using different type of traditional systems. Present time online examination system based on cloud computing concepts as well as various security monitoring techniques through the use of electronic and informational technology (IT) gave the surveillance report including monitoring system for taking corrective and preventive action. Hence the possibilities of making it more accurate information system, makes it, more efficient and more robust. Hence the use of online camera as popping up all over the place has become more efficient not only in the business industries but also in the shop floor practice, home applications, apartments, landmarks, schools, financial institutions, transportation center as well as use in medical science and space science have become more efficient. In this respect cloud computing also becoming more powerful network architecture. In this study the efficient use of cloud computing with respect to IP camera based is proposed.
\end{abstract}

\section{Keywords}

Ergonomics, Maintenance, Manufacturing process, Scalability, Triggering, Warehouse

\section{INTRODUCTION}

Cloud computing can be defined as utilizing the internet to provide technology enabled services to the people and organizations. It is an emerging internet based computing paradigm with its built in elasticity and scalability for delivering on demand information technology services to uses in a pay per use basic. Cloud computing has been promoted as a new paradigm and fifth utility services after water, elasticity, gas and telephone at presence a model in which information infrastructure is leased and used accordingly to the needs of an organization [12].

It is a model for enabling convenient on application and services that can be rapidly provisioned and released with minimal management effort or service provide interaction. Cloud computing are an application of technologies and a means of supporting the use of large scale internet services [14] called the remote application with good quality of services level.

\subsection{The Five Key- Characteristics of Cloud Computing}

\subsubsection{On Demand Self Service}

\subsubsection{Ubiquitous Network Access}

\subsubsection{Location Independent Resource Pulling,} Rapid Elasticity and Measured Service:

All of which are geared towards seamless and transparent cloud use [1], hence rapid Elasticity enables the scaling-up or down of resources. Measured services are primarily derived from business-model properties whereby could serviceproviders control and optimize the use of computing resources through automated resource allocation, load balancing and metering tools.

\section{VARIOUS USE OF CLOUD COMPUTING}

It emerges as a role model of business computing and very useful technology due to its ability to reduce cost associated with computing while increasing flexibility and scalability for computer process. Cloud computing also increases several security concerns [15]. Security has a constant issue for intimate as well as cloud computing. Cloud computing is surrounded by many security issues like security data and examining the utilization of cloud computing vendors which includes now-a-days in manufacturing system also.

\section{MODELS OF CLOUD COMPUTING i. Private Cloud. \\ ii. Public Cloud. \\ iii. Community Cloud. \\ iv. Hybrid Cloud.}

\section{DIFFERENT COST BENEFITS}

Cloud Computing is independent computing and it is totally different from grid and utility computing. Cloud Computing is cheaper than other computing models; zero-maintenance cost is involved. Since the service provider is responsible for the availability of services and clients are free from maintenance and management problems of the resources machines.

\section{CLOUD COMPUTING SERVICE MODELS

$\begin{aligned} \text { i. } & \text { SaaS (Software As A Service) } \\ \text { ii. } & \text { PaaS (Platform As A Service) } \\ \text { iii. } & \text { IaaS (Infrastructure As A Service) } \\ \text { iv. } & \text { LaaS (Learning As a Service) } \\ \text { v. } & \text { ElaaS (Education and Learning As a Service) }\end{aligned}$



vi. VSas (Video- Surveillance As A Service)
vii. Online Manufacturing \& maintenance of machines and its accessories Services Online

\section{PURPOSE OF INTERNET PROTOCOL CAMERA (IP CAMERA)}

IP camera designed for the use of

i. Security Surveillance in Industrial Engineering

ii. Bank and different Financial institutions

iii. Hospitals

iv. Office and commercial space

v. Casinos, hotel, restaurants

vi. Big bazaar like shopping centers

vii. City centers

viii. Outdoor and Indoor environment maintenance

ix. Manufacturing process, maintenance process (automation-maintenance process)

x. It includes automatic replacement of materials (automatic-warehouse system and material procurement receiving, retrieval as well as automatic inventory control system). It also includes automatic ordering, procurements as well as automatic forecasting.

xi. Ergonomics as well as the procedure of handling of each work.

xii. They are designed to meet and exceed the ever evolving demands placed all video security installation.

xiii. It offers the industries widest selection of fixed and positioning network camera system. Hence the open system delivers unparallel functionality, high resolution image, quality and full frame rate, video bringing clarity and precision to our various applications.

xiv. Offers facilities for night surveillance with night vision capability up to 15 feet in complete darkness.

xv. In enables uses for accessing from anywhere with a WI-fi, 3G, 4G connection

xvi. Triggering instant e-mail alerts and auto recording based on changes within your camera's environment due to motion sensing technology.

\subsection{The Special Uses of Cloud Computing With the Help of IP Camera-Based Online \\ i. Manufacturing Process \\ ii. Maintenance Process}
iii. Automation replacement of materials in automated ware house systems
iv. Ergonomics procedure in workshop practice
v. Design system for manufacturing in CAD
vi. Design of experiment (DOE) and Failure Mode and Effective Analysis (FMEA)

\section{MANUFACTURING PROCESS}

Particularly in, online production process or manufacturing process and online assembly processes, various processes or steps of operation have been collected through cloud computing. Hence in an organization may not have any work study (motion and time study) department but through cloud computing proper procedure of work and the duration (time) of particular work can be find out and that work can be performed systematically. It provides greater accuracy of the product.

\section{THE DIFFERENT STEPS OF OPERATIONS IN PATTERN MAKING THROUGH CLOUD COMPUTING}

In a manufacturing process, if opted for design process which includes the pattern making also, where all data for design including pattern allowances are also available directly through cloud computing.

N. B. For getting all those requires data in manufacturing or maintenance process, have to obtained Access/permission from a particular organization to whom to be paid earlier for obtaining the particular site with password by which we are directly getting the required data and that organization may be out of country from other places.

\section{COMPUTER AIDED DESIGN (CAD)}

In the following example in the case of Computer Aided Design (CAD), different types of use of IP Camera based been appended, where in every work station the use of IP Camera gives to rectify as well as make us to take preventive and corrective actions (Fig 1).

The main functions that would utilize the computer are through the use of cloud computing with the help of IP camera based online:-

$$
\begin{array}{cl}
\text { i. } & \text { Layout Design } \\
\text { ii. } & \text { Individual Component Modeling } \\
\text { iii. } & \text { Assembly Modeling } \\
\text { iv. } & \text { Interference and Tolerance Stack Checking } \\
\text { v. } & \text { Engineering Drawings }
\end{array}
$$

Use AGV in material management with cloud computing with respect to IP camera based online (Fig 2). Automation replacement of materials with the help of AGV (Automatic Guided Vehicles) or robotics or with belt conveyor. 


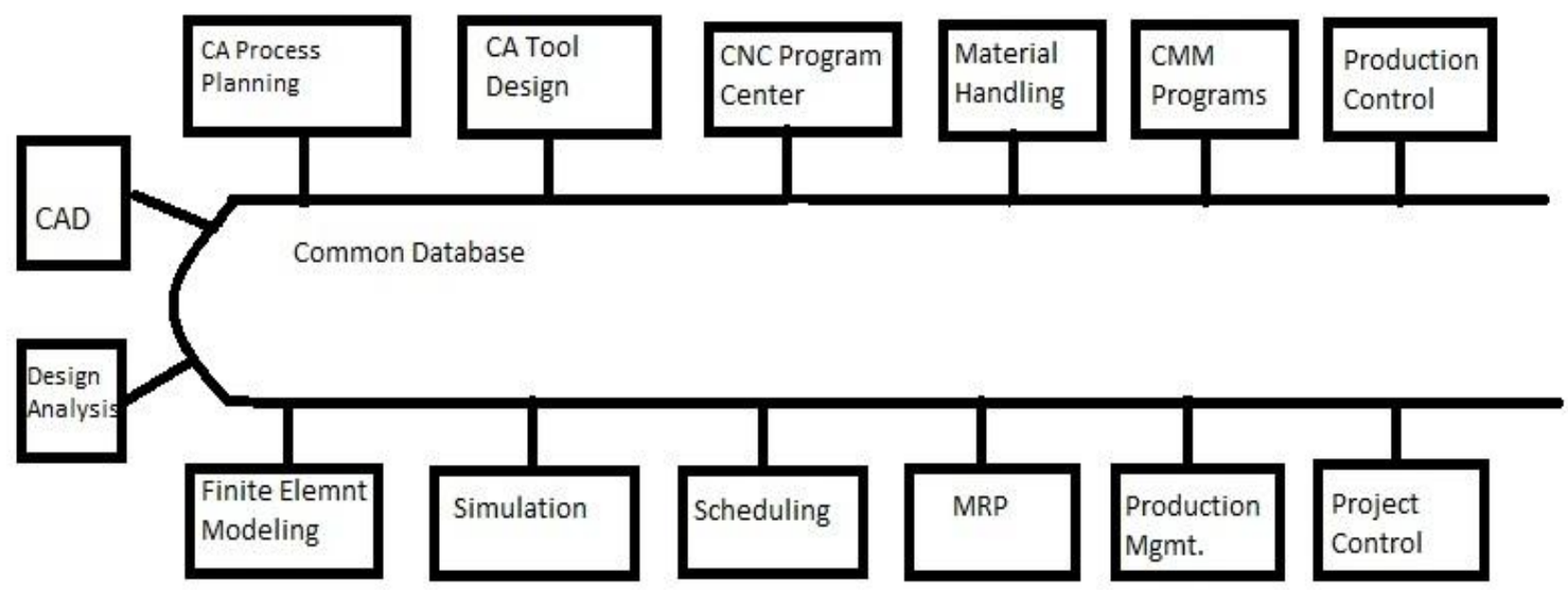

Fig: 1 The common database linkages to the various computerized applications in production process.

Unit Load

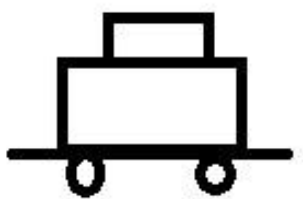

High rise-storage
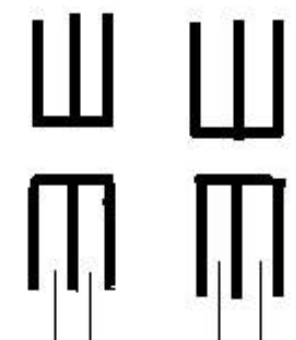

Conventional storage

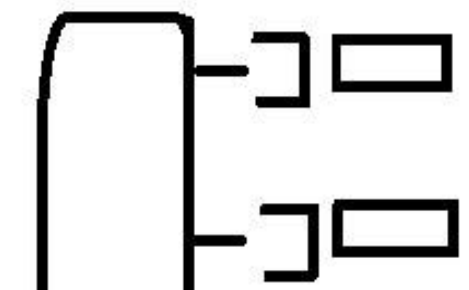

Receiving/ shipping

Sizing station

Fig: 2 AGV in online production 


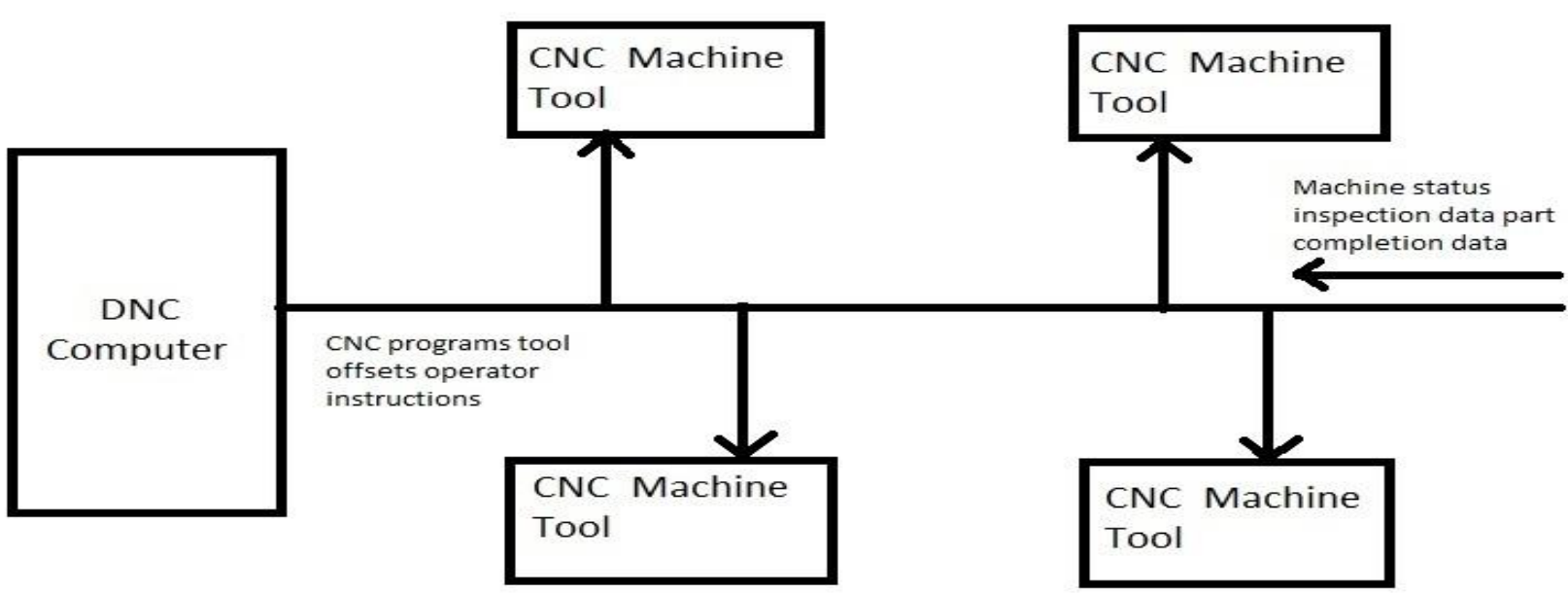

Fig: 3 Use computer interface with cloud computing with respect to IP based camera with cloud computing

\section{USE OF NC/CNC MACHINE WITH THE DIRECT NUMERICALLY CONTROL (DNC) WITH THE HELP OF CLOUD COMPUTING IP CAMERA BASED (FIG 3) \\ 11. ERGONOMICS PROCEDURE IN WORKSHOP}

This procedures mean proper gesture and posture doing or performing a particular work with proper motion and proper time with less human efforts and human efforts some places totally eliminated [7] and this can be done by cloud computing. For getting proper ergonomics the 5 steps $(\mathbf{5 - S})$ of KAIZEN process is used, Japanese process whereas 5-s, means Seiri, Seiso, Seiketsu and Shitsuke, a Japanese Technique for shop floor practice.

\section{AUTOMATIC NOTIFICATION THROUGH IP CAMERA BY CLOUD COMPUTING OF DIFFERENT STAGES OF PRODUCTION PROCESS}

Hence the different steps of operation may be designing for a particular product, material procurement, production planning (routing and scheduling) production control (dispatching and expediting or follow up), inspection and quality control, packaging and warehousing etc [13].

\section{CONNECTION OF IP CAMERA IS BASED ON \\ i. Wired Network- Ethernet cables or Fiber optics \\ ii. Wireless Network Wi-Fi routers or cellular network SIM cards}

\section{NEED FOR STATIC IP ADDRESS}

Network Cameras need Static IP address and only an Internet Service Provider can provide it on demand. Generally, when a device is connected to a network, one can access it by entering its IP address. But dynamic IP addresses change every time whenever anyone reconnect to a network. For this reason, static IP address is delivered to those devices which need to be consistently connected to a network. Sometimes virtual static IP address providers can also offer the service.

\section{CONCLUSION}

In this paper the various use of cloud computing with help of IP Camera based is presented. In this paper the concept of cloud computing is becoming more and more in the field of design process, manufacturing process, maintenance process including automatic materials management technique. This includes computer based fully automation in manufacturing. Hence in this study IP based camera been used particularly in the manufacturing process which gives the visual indication (ANDON) as well as (BAZZER) audio by which it enables the manufacturer to rectify preventive and corrective actions. So that rejection of the products and materials been eliminated. In the paper key security consideration and challenges which are currently faced in the cloud computing with the use of IP camera based are highlighted. This paper has shown the author's viewpoint on the use of cloud computing in supply chains of manufacturing industries to improve performance. For example, it provides for real time key performance (KPI) monitoring and prediction delivered to the smart phones of a plant manager or CEO. These advantages are enabling manufacturing plants across the world to gain unprecedented operation effectiveness, increase profits and reduce costs.

\section{ACKNOWLEDGMENTS}

Our special thanks to Dr. Neeraj Priyadarshi, Principal, Millia Institute of Technology, Purnea, who has motivated towards research writing in the area of Cloud Computing technologies which is built upon virtualization, distributrd computing and more recently networking, web and software services.

\section{REFERENCES}

[1] Ramgovind S, Eloff MM, Smith E, (2010), "The Management of Security in Cloud Computing, IEEE.

[2] FUNG, Eric, H.K., Chung, Allison, P.L. "Using ARMA models to forecast work piece roundness error in a turning operation", Applied Mathematical Modeling, Vol. 23, pp.567-585, 1999.

[3] Ruchita Chatterjee, Rudrani Chatterjee, Dippanita Jana, Dipak Ranjan Jana, "A Study on Automation and its Industrial Application" an International Journal 
(IJARSE) ISSN 2319 - 8354, Vol - 03, Issue 01, Jan 2014.

[4] Fung, Eric, H.K., Cheung, S.M., and Leung T.P., "Roundness Control in Taper Turning using FCC Technique", Proceedings of the American Control Conference, Albuquerque, New Mexico, pp.1068-1069, 1997

[5] CNC, MAZAK Lathe Step- 7 micro/ win 32, manual from Yamazaki Corporation.

[6] Reni Shaw apply innovation, H-2000-3020-06-A, Technical Specifications," Probing system for CNC machine tools".

[7] ^Rifin, Jeremy (1995), The End of Work: The Decline of the Global Labor Force and the Dawn of the Post Market Era, Putnam Publishing Group. pp 66, 75. ISBN 0-87477-779-8.

[8] ^Bennet 1993, pp.7.

[9] ^a b c Bennet 1979.

[10] ^ Bennet 1993, pp. 31.

[11] ^ Rifkin 1995.
[12] L.Wang, Gregor Laszewski, Marcel kunze, Jle Tao," Cloud Computing: A Perspective study", New Generation Computing-Advanced of Distributed Information Processing, pp. 137-146,vol. 28, no. 2,2008.DOI: 10. 1007/s00354-008-0081-5.

[13] Harold C. Lin, Shivnath Babu, Jeffrey S, Chase, Sujay S. Parekh, "Automated Control in Cloud Computing: Opportunities and Challenges", Proc. of the $1^{\text {st }}$ Workshop on Automated control for data centres and clouds, New York,NY,USA,pp.13-18,2009,ISBN:978-160558-585-7.

[14] Neal Leavit, "Is Cloud Computing Really Ready for Prime Time?"Computer, vol. 42, Issue. 1, pp. 15-20, IEEE Computer Society, CA, USA, January 2009.ISSN:0018-9162.

[15] Richard Chow, Philippe Golle, Markus Jakobsson, Elaine Shi, Jessicca Staddon, Ryusuke Masuoka, Jesus Molina, "Controlling Data in the Cloud: Outsourcing Computation without outsourcing Control", Proc. Of the ACM Workshop on Cloud Computing Security, pp. 8590, USA, November 2009.ISBN:978-1-60558-784-4. 